\title{
Research on the Gender Difference of the Children in Family Conflicts
}

\author{
Zhou Shen \\ Jinan Foreign Language School, Jinan, Shandong province, 250000, China \\ Corresponding author's e-mail:Vivian.wang@cas-harbour.org
}

\begin{abstract}
With the rapid development of the society and the competition of educational resources, the education of children has attracted more and more attention of parents. Furthermore, with the traditional mindset of parents, conflicts are inevitable. At present, it has been found that in most of the families there are conflicts between parents and children, which may be caused by various reasons, like the improper communication or lack of communication. Although there are many research, not many people have noticed that there may be some differences between girls and boys. Commonly, boys are more aggressive than girls, since in their teenage time, boys secrete more androgen than girls, which can make them more aggressive. In contrary, girls have stronger willingness and better ability to communicate. Hence, there may be different reasons or different consequences between family conflict considering the gender of the children. By observing the target groups-teenagers age around 12 to 19, it comes to the conclusion that boys are more likely to have physical conflict with their parents, while girls have emotional conflicts. Furthermore, different family structures can lead to different kinds of family conflicts. Furthermore, we had concluded that mothers are more likely to have conflicts with their children compare with fathers, and the conflict between mothers and girls are more than mothers and boys since children might think that they feel more equally with their father than mother. Therefore, people should pay attention to both the gender of the children and the family structures, when they attempt to reduce their family conflicts.
\end{abstract}

Keywords: Family conflicts, gender, age, parent-child-triangulation, family relationship

\section{INTRODUCTION}

Family conflicts exist in most of the families and it is a difficult problem for them to solve. There are several factors that lead to family conflicts, such as the way of communication between family members, the distribution of love of parents to their children, or the status of different family members. This research focuses on the gender differences of the children when facing family conflicts. Besides, how the family structure affects the relationship between parents and children will also be investigated.

The main research questions of this paper are: how gender differences exert effect on family conflicts, what the cause of the conflict in both boys and girls is, and how to decrease the frequency of family conflicts. By sending questioners, the main cause of family conflicts and the frequency of the existence of conflicts can be observed.

The author expects to get more specific information, like the cause of the conflicts and get more comprehensive information, like some results that have already been observed by researchers by literature review.

\section{RESEARCH ON THE PARENT-CHILD- RELATIONSHIP}

\subsection{Family structure and parental marital status}

In a remarried family, although teenagers can accept the new family more quickly than younger children, it is hard for them to adapt to it. Children tend to rely on their biological parent than their step parent, when they have conflicts. Besides, children are more likely to be more loyal to their biological parent. Since the lack of communication and trust, conflict between children and parents exist. However, the change in family structure can have different influence in boys and girls. Boys are more likely to be negatively influenced than girls. In addition, if boys live in a family where they have no or scarce contact with their fathers, they tend to form bad habits like alcoholism or addiction to drugs. [1].

\subsection{Parental Gender Interaction}

The relationship between parents and children has a lot difference and might change during children's teenage time. Since children may contacting with their mother more often 
than their father during their early teenage time, so the frequency of conflicts between mothers and children are greater than that between fathers and children. The most serious conflicts between children and their mothers is around their $15 \mathrm{~s}$. Afterwards, the frequency will decrease, till they reach 17, while, the frequency of conflict between children and their fathers will increase.

The relationship between fathers and children are likely to be more equal compare to the mother-child-relationship[2]. Research shows that no matter what is the gender of the children, mother will have more conflicts with them than their father, especially girls, since mother might have more involvement to the children's life than father[1]. Research progress of parent-child relationship. Since mothers are used to be girls, they know more about what a girl should do. Therefore, they might pay more attention and put forward more requirement on their daughters than sons, thus enhancing the possiblities of conflicts between them and their daughters.

Due to the stereotype of the society, most of the people think that it is women's duty to raise the children[1]. Furthermore, the society has a structure that being urgent, sometimes when a event happened, there is not time for the family to sit down and have a conversation or having introspection.

\section{RESEARCH ON THE PARENT-CHILD- TRIANGULATION}

Parent-child-triangulation is a smallest unit to maintain the family's emotional system, which contains different reactions and feelings the children will have when their parents may arguing. This triangulation contains three basic categories, namely, the scapegoating, the parentification and the cross-generational coalition. Scapegoating is a situation where parents take care of their children or parents go discipline their children. Parentification is reversal of the role between parents and children that the emotion that children hide switches to the feelings that they have to take care of their parents, like the children have to a lot of chores when their parents have a fight. The cross-generational coalition refers to the situation that children are on one side of their parents. Furthermore, there are two situations: fixed alliance and unfixed alliance. There are still disagreements on the gender differences in the parent-child-triangulation. Here are some results of the difference in gender effect parent-child triangulation.

Table 1. Different sayings about parent-child triangulation[3].

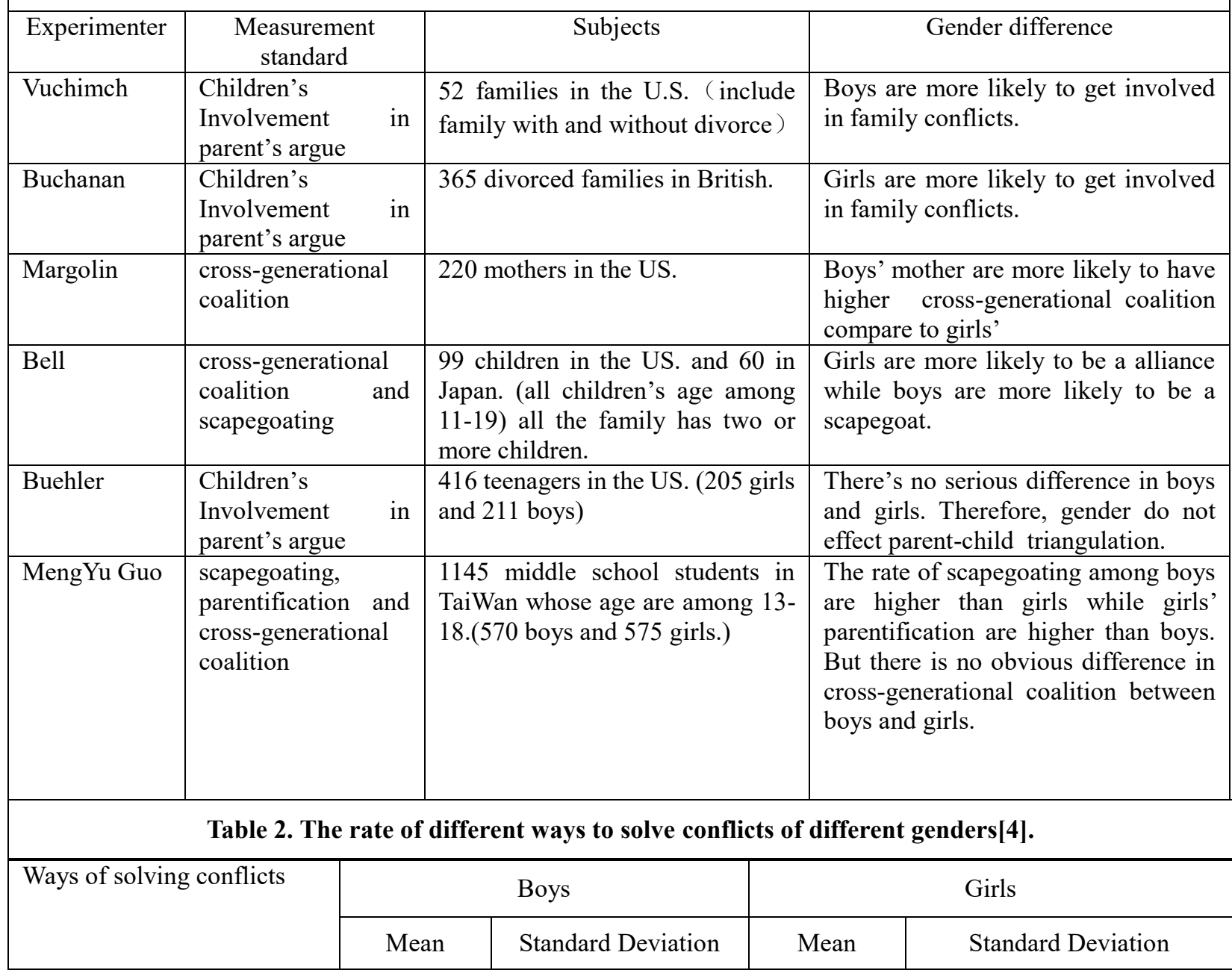




\begin{tabular}{|l|l|l|l|l|}
\hline Solving the problem & 2.55 & 0.56 & 2.58 & 0.62 \\
\hline resistance to attack & 1.69 & 0.50 & 1.84 & 0.54 \\
\hline Conflict avoidance & 2.40 & 0.56 & 2.40 & 0.58 \\
\hline concession & 2.55 & 0.61 & 2.37 & 0.67 \\
\hline Mediation by others & 1.72 & 0.62 & 1.63 & 0.59 \\
\hline
\end{tabular}

\section{GENDER DIFFERENCES OF THE CHILDREN WHEN DEALING WITH CONFLICTS}

There are some different strategies to solve the conflicts between parents and children, which are question solution, concession, evade, resistance to attack and regulation by others.

Girls have higher scores on solving questions and resistance to attack, while boys have higher scores on regulation of others and concession. In girls' brains, the areas responsible for expressing and processing complex emotions are more developed, and relatively speaking, the areas in boys' brains that deal with simple, direct emotions are larger. That is why boys are often indifferent to the things that make girls feel depressed. Moreover, they are more likely to be irritated in the battle. These differences lie in the brain structure. When girls are three or five years old, they can show more thoughtful qualities. On the contrary, boys behave more directly and confrontationally. They often give up verbal expression and choose physical movements to solve problems.

As shown in Table 2, the mean frequency of the ways boys and girls used when facing family conflicts is calculated.

\section{SPECIAL TIME FOR CHILDREN AND PARENTS}

Teenage time is also one of the most important period in a person's life, when a person changes from child to adult. In this period, children may change a lot, not only on the appearance, but also on the way of thinking and behaving. For example, they may consider themselves as adults and refuse to obey what their parents have told them. Furthermore, in this period, children are more likely to regard the way and the tone people speak to them as one of the important things. What is more, boys and girls start to develop their secondary sexual characteristics[5].

Since many children still attend school when they are around 12-19, different people will have different reaction when they are facing pressure, and those feelings or the reaction they react when dealing with stress can be different among boys and girls. Girls are more likely to have more negative emotions than boys and they will be anxious when they know that some tests are coming [6]

Girls and boys also have different capabilities of dealing with their emotions in different ages. There is no obvious difference before 15 years old. Whereas, girls start to be better at controlling their emotions than boys, when they are around 16. However, this ability will become almost the same by their $18 \mathrm{~s}$ among all the children.

Furthermore, the conflicts between parents and children have something to do with the age of them, since the children are in teenage time and they are more likely to have some changes in their emotional states. For example, they can be more easily to be angry and they pay more attention to the way their parents or other people talk to them. However, the age of their parents are in the stage called climacteric, which is also an important stage in a person's life. People are often manifested in this stage as low mood, depression, anxiety, slow thinking, unresponsiveness, lack of energy, lack of ability to do things, not interested in the things they were used to like, and gaining weight. Also, people in this stage tend to worry about their children's future, while their children might think that they care and control them too much, thus resulting in conflicts.

\section{SUGGESTIONS}

Since the conflicts is between parents and children, so that the solution can come up with both of their sides.

\subsection{Consider solutions based on the children's situation}

\subsubsection{Perspective taking}

No parents will do harmful things to their children on purpose. What they do is always trying to create a better future for their children. However, sometimes the way they act might do harm to their children. But if the children can put themselves in their parents' shoes, they might understand their parents.

\subsubsection{Try to communicate more with their parents}

Communication is the best thing that can unravel all misunderstandings. By communicating and expressing their feelings to others, they can understand each other more easily. Also, they can know better about each other, thus making their relationship better. 


\subsection{Consider solutions based on the parents' situation}

\subsubsection{Do not be too nagging, listen more to what the children's speaking}

Everyone's patience is limited, therefore, parents should not repeat their requirement again and again, or their children will get bored and may lead to family conflict.

\subsubsection{Give your child enough private space}

While maintaining intimate relationship with children, it is really difficult to give children enough private space. However, it is necessary to protect children's private space and give them more freedom, when they are getting older. It is necessary for parents to know that it is impolite to peep at their children's diaries and turn over their children's schoolbags.

\subsubsection{Seize the opportunity to praise the children}

When the children make the right decision or do a good job at something, parents should seize the opportunity to praise them. Praising will make them feel that their decisions and success are valued, and that their abilities are recognized by their parents.

\subsection{Different ways for girls and boys}

\subsubsection{For girls}

Girls have stronger neural connections in the temporal lobe, which promotes the storage of more complex sensory memories and better hearing, making girls particularly sensitive to the tone of the voice. It is better for them to develop the ability to be more confident and trust in themselves.

\subsubsection{For boys}

Boys should try to think twice before doing any actions, to make sure that their action will not let their parents worry about them. The frontal lobe of boys is not as active as that of girls and develops later, so boys tend to make impulsive decisions.

\section{CONCLUSION}

From the research, it can be inferred that the conflicts between girls and mothers are obviously more than those with fathers, while boys only show significant differences in daily life. Boys have more conflicts with their mothers than their fathers in daily life. In addition, boys are more likely to have physical conflicts with their parents, while girls have emotional conflicts. There are several suggestions that might decrease the frequency of family conflicts, which take the gender of children into consideration, and can be divided into two parts which are parents' situation and children's.

The limitation of this research is that the people who filled this questionnaire are the people who the author is familiar with or the people live in the same city with the author. To reduce the deviation as much as possible, in the latter part of the research, the author can do some interviews and post more questions to more people in different places to increase the accuracy of the research.

In the end, the relationship between parents and children is one of the most important element for the growth and development of a children. Therefore, the author hopes that everyone can deal with their relationship properly.

\section{ACKNOWLEDGMENT}

The author would like to thank all the people who had helped me to finish this paper, to the people who filled the questionnaire, to the people who modified this paper.

\section{REFERENCES}

[1] Y,Chen, Research progress of parent-child relationship, 22//12/2014, accessed on 14/5/2020, https://wenku.baidu.com/view/9f658f970242a8956bece 4b2.html?fr=search

[2] D. D. Zheng, An Analysis of the Cause of Parent-Child Conflict_Interpretation of Non-Gender and Gender Perspectives. 20/3/2015, accessed on 14/5/2020, https://wenku.baidu.com/view/ d20ec5febceb19e8b9f6b a54.html?fr=search

[3] M. P. Wang. Gender differences in the parentchild triangle relationship, 11//10/2016, accessed on $14 / 5 / 2020$,

https://wenku.baidu.com/view/9a6a21e2964bcf84b8d57 b27.html?fr=search

[4] Xingmxy, 14//3/2014, accessed on 16/5/2020, https://wenku.baidu.com/view/c6dd228658f5f61fb7366 $67 \mathrm{c} \cdot \mathrm{html}$ ?fr=search

[5] Sohu. 10 natural differences between boys and girls, 16/2/2018, accessed on 20/5/2020, https://www.sohu.com/a/222933600_361776

[6] Y. X. Shu. Ten natural differences between boys and girls, $7 / 1 / 2018$, accessed on 21/5/2020 https:// wenku.baidu.com/view/b5ebdc68f12d2af90242e 679.html. 